\title{
Heartache of the State, Enemy of the Self: Bipolar Disorder and Cultural Change in Urban China
}

\author{
Emily Ng
}

Published online: 13 June 2009

(C) The Author(s) 2009. This article is published with open access at Springerlink.com

\begin{abstract}
Past works in anthropology and psychology have described the Chinese orientation toward life as situation-centered with an external locus of control. This model has also been applied to the understanding of affect disorders in China-depressive patients have been found to focus on outside circumstances surrounding dysphoric moods. However, dramatic economic, sociopolitical and cultural changes in post-Mao China may be affecting these cognitive orientations toward emotional distress. This paper focuses on the subjective experiences of individuals diagnosed with bipolar disorder in China. The study is based on semistructured interviews with patients at a Western-style mental health institution in Shenzhen, the first successful Special Economic Zone in China. My data suggest that the location of agency has shifted across generations. Whereas those who grew up in the Maoist era are inclined to use external circumstances to explain the control over and responsibility for their illness, younger patients tend to emphasize self-blame and individual responsibility. I argue that these intergenerational differences in ethnopsychology relate to the multifaceted rise of individualism in post-Mao China. The paper ends with an examination of this observed shift vis-à-vis recent theories of neoliberal discipline in China and a discussion of potential psychological implications.
\end{abstract}

Keywords Bipolar disorder - Cultural change - Cognitive orientation · Emotion · China

E. $\mathrm{Ng}(\bowtie)$

Department of Anthropology, University of California, Berkeley, 232 Kroeber Hall,

Berkeley, CA 94720, USA

e-mail: emily.ng@berkeley.edu 
Causation of mental disease is such a complex interaction between biological and psychological and social sources of vulnerability ... that the term causation itself can be misleading.

—Arthur Kleinman (1988)

I've been trying to just be content with things over the years, to appreciate the simple life I lead.... But sometimes I still think to myself: Why me?

-Ms. Shan, patient diagnosed with bipolar disorder (Shenzhen 2005)

\section{Introduction}

When faced with the predicament of having become 'mad' under the psychiatric gaze, or, worse yet, in the eyes of those closest to you-family, friends, coworkershow does one go about explaining what has occurred? How might cultural models of agency, influenced by global flows of scientific and economic discourses, impact how one thinks and speaks about what happened? This study seeks to explore the subjective experiences of individuals diagnosed with bipolar disorder in Shenzhen, a southern Chinese city that transformed from a small fishing village to a booming metropolis of more than 12 million in less than 30 years. Previously, anthropologists and cross-cultural psychologists have found that the Han Chinese ${ }^{1}$ often perceive control over life and illness as external to the self (Hsieh et al. 1969; Hsu 1949, 1971; Kleinman, 1980; Kuo et al. 1979). In this paper, I suggest that the rising cultural significance of the individual evidenced by recent anthropological studies, tied to decades of sociopolitical change and the entrance of global capitalism in China, is reflected in a shift in cognitive orientation between generations of bipolar patients. Within the group of 15 people diagnosed with bipolar disorder I interviewed in Shenzhen, those who had grown up in the Maoist era were inclined to explain control over and responsibility for their illness as external to the self, but youth of the postMao generation largely emphasized personal responsibility and self-blame. I present and analyze four cases in detail, and conclude by discussing some potential clinical and social implications of this psychocultural shift.

\section{A Madness of Moods: An Overview of Bipolar Disorder}

Bipolar disorder is defined by Western psychiatry as a severe, recurrent mental illness involving abnormal mood cycles with highs of mania (or hypomania) and lows of depression that can both escalate to psychosis. It has been considered the sixth leading cause of disability worldwide among all physical and mental illnesses by certain measures (Murray and Lopez 1996). The diagnosis of bipolar disorder in both the United States and China are based on similar Western psychiatric criteria. Since

\footnotetext{
1 In this paper, the term 'Chinese' refers to the majority Han ethnicity. Citations of research on 'Chinese' culture and psychology, usually used by the authors to describe the Han majority, may not apply to other ethnicities residing in mainland China or other Han-populated locales. All my interviewees were of Han descent.
} 
my inclusion criteria were based on the North American definition of bipolar disorder (notably, the allowance for cases that involve manic episodes without past diagnosed depressive episodes), I outline the (DSM-IV) (Diagnostic and Statistical Manual of Mental Disorders [American Psychiatric Association 2000]) description here.

In the DSM-IV, a manic episode is said to be "a distinct period of abnormally and persistently elevated, expansive, or irritable mood, lasting at least 1 week (or any duration if hospitalization is necessary)," involving at least three symptoms such as inflated self-esteem or grandiosity, decreased need for sleep, increased talkativeness, flight of ideas or subjective experience of racing thoughts, distractibility, increased goal-directed activities and excessive involvement in pleasurable activities that have a high potential for painful consequences. A major depressive episode has at least five symptoms lasting 2 weeks, requiring either depressed mood or loss of interest/pleasure, and may include symptoms such as a depressed mood, diminished interest or pleasure in activities, significant weight loss or weight gain unrelated to intentional dietary changes, insomnia or hypersomnia, psychomotor agitation or retardation, fatigue or loss of energy, feelings of worthlessness or excessive guilt, diminished ability to think, indecisiveness and recurrent thoughts of death or suicide (American Psychiatric Association 2000). The Chinese Classification of Mental Disorders (CCMD-3), published by the Chinese Society for Psychiatry in 2001, differs in several details in diagnostic criteria, which are not discussed here since the differences are not significant for the present purposes. The most significant difference is the retention of the category recurrent (unipolar) mania, which had been discarded in the DSM-IV and ICD-10, but remains relevant in China (Lee 2001) and other non-Western countries (Lee and Yu 1994).

Cross-national surveys of bipolar disorder have found prevalence rates ranging from $<0.5$ to $1.5 \%$ (Weissman et al. 1996). An increase in the diagnosis of bipolar disorder can be seen in epidemiological surveys in both the United States and China over the past few decades. One large-scale survey in the United States-the Epidemiologic Catchment Area program of the National Institute of Mental Healthfound a $1.2 \%$ lifetime prevalence rate of bipolar disorder (including I and II) on average (Weissman et al. 1988). More recently, the U.S. National Comorbidity Survey Replication found a 2.6\% 12-month prevalence and a 3.9\% lifetime prevalence rate of bipolar disorder (including I and II) (Kessler et al. 2005a, b). For the past three decades, some researchers in the United States have been arguing for the notion of bipolar disorder as a broader spectrum of illnesses. Under this expanded definition, the U.S. prevalence rate would be increased to approximately $5 \%$ by including milder forms of bipolar disorder with a predominantly depressive symptomatology, the so-called bipolar spectrum disorders (Akiskal 2002).

In China, researchers have documented low rates of bipolar disorder relative to the West, although the figures have increased across past decades. Prevalence rates for bipolar disorder ranged from 0.003 to $0.009 \%$ in Chinese epidemiological reports between 1958 and 1979 (Lin and Kleinman 1981), and from 0.037 to $0.089 \%$ in nationwide surveys of the 1980s (Cheung 1991). A recent study involving face-to-face household interviews with 5,201 subjects in Beijing and Shanghai found the 12-month prevalence of bipolar disorders (including bipolar I and II) to be $0.1 \%$ (Shen et al. 2006). However, it is unclear whether these rates 
accurately reflect the number of afflicted individuals, since community epidemiological estimates have been fraught with numerous methodological difficulties (such as unwillingness to reveal past core diagnostic mood symptoms during faceto-face interviews with strangers). Despite this, mania is one of the most common illnesses treated by Chinese psychiatrists in clinical settings (Sing Lee, personal communication). Moreover, regardless of the numbers, bipolar disorder-along with schizophrenia-is considered a severe mental illness in China (Pearson 1995).

\section{Subjectivity, Cultural Process and What's at Stake}

Several interrelated theories have been impacting the anthropological study of mental illness. Jenkins and Barrett (2004, p. 7) write, "A theoretical move toward subjectivity has taken hold in anthropology at a time when retreat from this domain of inquiry has largely taken place in psychiatry and psychology." The authors indicate that this shift toward subjectivity stems from three growing anthropological concerns: prioritizing lived experience over analytical categories, emphasizing subjects' agency in cultural processes and bridging individual experience and social reality through the notion of intersubjectivity. These changes in theoretical orientation critically address increasingly experience-distant psychiatric approaches and problematize past poststructuralist accounts of mental illness that fail to account for human suffering and individual experience (Burr and Butt 2001).

An important figure in this anthropological dialogue has been Arthur Kleinman, who studied neurasthenia and depression in mainland China and Taiwan throughout the 1970s and 1980s. Kleinman's works $(1980,1986)$ have illustrated the importance of an experience-near approach to mental illness. While his extensive work on neurasthenia and depression lays a strong foundation for the study of affect and illness in Chinese society, he methodologically precluded bipolar patients from his studies. I hope that by focusing on bipolar disorder, this project can build on previous studies of affect, illness and contexts of suffering in China, particularly in the context of the rapid sociopolitical changes that involve new questions of illness, emotion and agency. I discuss these substantive and contextual distinctions below.

\section{Emotion, Illness and Sociopolitical Landscapes}

When Deng Xiaoping and his colleagues took leadership after the death of Mao in 1976, they began to implement major reforms that would not only impact the economic and political orientations in China, but also transform the social and emotional domains. In Maoist China, personal problems were moralized and politicized rather than medicalized and psychologized as in the West (Kleinman 1980). Time outside of work became highly regulated. Leisure took place in group settings, and failure to participate in state-sanctioned leisure activities provided grounds to criticize individuals for "cutting themselves off from the masses" and "lacking collective spirit" (Wang 1995, p. 153). In this context, depressive symptoms such as social withdrawal and the loss of drive could be politically risky 
if not concealed (Lee 1999). Furthermore, depression was viewed as ideologically undesirable during the Cultural Revolution (1967-1977), since mental illness was viewed as a problem caused by capitalistic systems and was not supposed to exist in the socialist state (Cheung 1991; Lee 1999).

In this sociopolitical climate, the label of neurasthenia (a psychosomatic illness involving fatigue, weakness and generalized pain) provided a medically legitimized, body-based idiom through which to communicate distress (Kleinman 1986). This medical category not only provided a way to avoid the stigma of mental illness, but allowed patients to safely express their grievances in an environment where any politically dangerous move could subject an individual to forced labor, beatings, torture and public humiliation (Fairbank and Goldman 1998). The Cultural Revolution embedded a sense of pervasive fear that rendered terror a common emotional state in everyday life (Kleinman and Kleinman 1991).

In the 1980s, the new leadership under Deng loosened state control over most domains of social, cultural and personal life (Goldman 1998). New urban sites including billiard parlors, bars and beauty shops have shaped patterns of consumption and city culture. Economic and sociopolitical decentralization have opened new physical and social spaces for personal autonomy and subjective experience (Davis 1995). Parallel changes in the socioemotional landscape have also been documented in rural areas in China. In his ethnography of a northeast Chinese village from 1949 to 1999, Yunxiang Yan (2003) documents the increasing emphasis on emotionality and the growth of youth autonomy. Broadly speaking, social life in both urban and rural areas has become increasingly depoliticized, and public discourse on mood and emotion has become less dangerous and more commonplace. Ordinary citizens could now openly express opinions, hopes and fears on an individual level (Link et al. 2002). Popular media and professional literature have begun to utilize terms such as psychological (xinli), stress (yali), mood (xinqing) and depressed (уоиуи) more regularly (Feng 1996). These sociopolitical changes form new contexts for the experience of affect and illness in China that differ greatly from the sociohistorical environment Kleinman's interviewees lived through.

\section{Psychiatry and Depression after Reform}

In the 1980s, foreign pharmaceutical companies that were previously banned in Maoist China were allowed to enter the country and influence mental health professionals and the general public through advertisements, educational seminars and academic conferences. ${ }^{2}$ Sing Lee (1999) inspects these processes of globalization and their implications by tracing the fate of neurasthenia as a diagnostic category in post-Mao China. Lee notes that in an attempt to encourage the use of new selective serotonin reuptake inhibitor (SSRI) antidepressants in China, one drug company has strategically used Kleinman's (1982) research to advertise

\footnotetext{
${ }^{2}$ For instance, during my research, Kangning Hospital regularly hosted public education seminars on various mental health topics funded by Eli Lilly.
} 
Table 1 Familiarity with psychiatric terms among the general public in Shenzhen: $n=60$

\begin{tabular}{llll}
\hline Term & $\begin{array}{l}\text { Never heard } \\
\text { of term }(\%)\end{array}$ & $\begin{array}{l}\text { Heard of term } \\
\text { but did not know } \\
\text { basic definition }(\%)\end{array}$ & $\begin{array}{l}\text { Heard of term } \\
\text { and did know } \\
\text { basic definition (\%) }\end{array}$ \\
\hline Bipolar disorder (shuangxiangzhangai) & 91.67 & 6.67 & 1.67 \\
Manic depression (zaoyuzheng) & 73.33 & 6.66 & 20.00 \\
Depression (yiyuzheng) & 18.33 & 0 & 81.67 \\
Schizophrenia (jingshenfenliezheng) & 15.00 & 3.33 & 81.67 \\
\hline
\end{tabular}

neurasthenia as a pharmacoresponsive form of biological depression. While pharmaceutical companies employ comparable marketing tactics in the United States, Lee cautions that the scarce access to new scientific literature, the lack of consumer activism for psychiatric patients' rights and a peculiar power differential between pharmaceutical salespeople and psychiatrists (the sales staff income is considerably higher than that of the doctors) make the marketers' impact particularly salient. Pharmaceutical companies have also manipulated the notion of renqing - a humanistic exchange of favors-to request leading academic psychiatrists to give promotional lectures after funding their costly travels to international conferences.

The exact impacts of foreign pharmaceutical marketing are still unclear. Sing Lee (1999, p. 361) hypothesizes that "as the therapeutic culture begins to appropriate demoralization, direct affective expression among psychiatric patients is likely to become more common in the future." Indeed, at the time of my research in 2005 , the term depression (уіуи or уоиуи) seemed to have taken on two lives in contemporary China already: one as an illness and another as a normative mood that does not warrant help seeking. With the influence of foreign pharmaceutical companies, availability of glossy psychology magazines at newsstands, popularization of psychology talk shows on television and radio, increased mental health education campaigns by the government and easy access to pirated foreign films and soap operas, many Chinese in Shenzhen are well aware of the concept of depression (see Table 1). During my fieldwork, I encountered many people (unrelated to my hospital research) who used the terms yiyu (closest to "depression" and formally used in CCMD-3), уоиуи (anxiety-depression) and yumen (depression-stuffiness; a term recently popularized among younger people) to refer to everyday feelings that they did not consider pathological. As one middle-aged taxi driver responded when I asked him about the term depression, "Ha! Of course I have heard of depression! Everyone has had depression, right? We all get depressed sometimes!"

\section{The Cultural Significance of Mania}

Prior to the growth of Western psychiatry in China, what would be considered depressive symptoms from the psychiatric perspective were incorporated into a psychosomatic Chinese medicine framework (Lin 1981). In the Huang-ti 
Nei-ching, ${ }^{3}$ The Yellow Emperor's Classic of Internal Medicine translated by Henry $\mathrm{Lu}$ (1978), the question is posed: How do we draw a distinction between "insanity" (kuang, the same character still used in the contemporary clinical terminology for mania, zaokuang) and "madness" (dian)? The text states that "when insanity (kuang) attacks, the patient will have little sleep, absence of hunger, with a boosted ego, being arrogant, laughing in an insane manner, singing, and being constantly active." This description is very similar those of early Greek as well as contemporary psychiatric descriptions of mania. On the other hand, the "mad" (dian) patient is described as "unhappy, falling to the ground with eyes looking straight, and the pulse will be strong in three regions at the wrist." While the "unhappy" element of dian can be viewed as parallel to contemporary psychiatric notions of depression, the latter part of the description seems to point more directly at epileptic symptoms. Since psychological problems producing "dramatic or erratic effects" posed difficulties for this highly developed and usually self-sufficient explanatory system, and were "sometimes treated separately" in classical Chinese medicine (Lin 1981), it seems likely that depressive symptoms not associated with the extremities of seizures would not be problemetized in the same manner as manic symptoms.

Thus, while Western psychiatrists theorize depression and mania as two cycling components of a single disease entity, traditional Chinese medicine viewed them as distinct phenomena. In an article summarizing the first 10 years of psychiatric work after the founding of the People's Republic, "quarrelsome excitement" is framed as the "most pronounced symptomatic group of mental diseases" in the Chinese context, creating destructive results in interpersonal relationships (Wu 1959). Thus, the manic aspect of bipolar disorder holds distinct ontological relevance in Chinese societies, where the emphasis on interpersonal harmony has been considered core to one's personhood (Ho 1991; Hsu 1971; Hwang 2000). One caveat that is not discussed at length here is the relationships among cultural change, capitalism and the potentially changing significance of mania in China. During my fieldwork, there were hints that the values and troubles of mania are highly context- and person-dependent and that, when associated with contexts of intense competition, manic and hypomanic characteristics are increasingly valued, with some symbolic parallels to Emily Martin's (2007) descriptions of mania and capitalist culture in the United States.

\section{Shenzhen as an Urban Embodiment of Post-Mao China}

The present study took place in Shenzhen, a southern coastal city in the Pearl River Delta established as a Special Economic Zone at the start of Deng Xiaoping's

\footnotetext{
${ }^{3}$ The Huang-ti Nei-Ching is a classic text considered foundational to traditional Chinese medicine whose precise origins remain debated. Its ideas likely emerged from lengthy oral histories, with estimated dates of writing - including versions layered with commentary and revision-as early as the fourth century BCE (Unschuld 2003) and as late as the first century BCE (Sivin 1993). The translated editions differ in approach and interpretation, and some believe that translations of such classic Chinese medical texts fall below precision (Sivin 1988). Despite the complications, its contents remain an interesting point of reference and comparison in this context.
} 
economic reform era in 1979. Shenzhen is a particularly interesting site for research in contemporary China since it was singled out by Deng to symbolize and embody China's future after Mao. In the span of 25 years, Shenzhen has exploded from a fishing town with several thousand residents to a skyscraper-jammed metropolis with a population of at least 12 million (Chen 2005).

During the Maoist era, the salt-saturated soil in the Pearl River Delta where Shenzhen is located was considered unfit for intensive cultivation. Thus, it was not a priority area for agricultural development. Furthermore, its proximity to capitalist Hong Kong - just across a narrow stretch of water and within view of its shoresexcluded Shenzhen from prime government budget allocations (Lin 1997).

Shenzhen's status changed dramatically in the late 1970s. Armed with new slogans of "To get rich is glorious" and "[The state should be] acting according to objective economic laws," Deng ushered in a new era for Shenzhen, whose geographic and symbolic location mutated into assets under the values of reform (Cannon and Jenkins 1990, p. 11; Fairbank and Goldman 1998, p. 412; Lin 1997). Furthermore, rural-urban migration to Shenzhen and other urban areas became a common method of youth escape from rural unemployment and poverty, as previous policies that tried to absorb surplus unemployment were dismantled with the onset of the reform era (Lee 1998). Due to a combination of Deng's political and economic endorsement, rural poverty and unemployment, tax and bureaucratic exemptions for investors and media hype, Shenzhen has attracted millions of migrants, particularly young "floating" labor migrants from inland and investors from Hong Kong and abroad. The city contains migrants' hopes and dreams, yet is also rampant with insecurities and love-hate sentiments ( $\mathrm{Lu}$ et al. 1999). Despite the prosperity and hailed success of Shenzhen, it has also become a site of economic inequality, labor grievances, crime, prostitution and drug trafficking (Chen 1999; Deng 2001; Lau et al. 2002; Thireau and Hua 2003; Zhao 2000). All in all, Shenzhen is one site that epitomizes the desires and disillusionments pervasive in contemporary urban China.

\section{Methods}

This paper derives from research in summer 2005 at Kangning Hospital, a Westernstyle psychiatric hospital also known by the name of Shenzhen Institute of Mental Health. Kangning Hospital was founded in 1985. The hospital consisted of a threestory outpatient ward and a six-story inpatient ward with 262 beds at the time of research. While there were several general hospitals with mental health care components in Shenzhen, Kangning was the only professional institution dedicated to the treatment of mental illness.

The data presented below are based on semistructured, open-ended interviews I conducted in Mandarin with 15 individuals diagnosed with bipolar disorder (both inpatient and outpatient) and six family members of those diagnosed with bipolar disorder (three with their diagnosed relative, three without). I held a single interview with most participants and two with a pair of patients. Interviews lasted approximately $1 \mathrm{~h}$ each. Hospital psychiatrists were asked to refer any patient with a diagnosis of 
bipolar disorder, including recurrent mania, who was in stable condition. Not all psychiatrists in the hospital participated. The project was introduced to hospital psychiatrists as an exploratory project on Chinese patient experiences of bipolar disorder. The psychiatrists were not aware of any hypotheses related to the project; in fact, the argument made here was not conceptualized prior to the research but, rather, surfaced during data analysis.

I designed the interview schedule with reference to Mitchell Weiss' Explanatory Model Interview Catalogue (EMIC), Young and Kirmayer's Illness Narrative Interview Protocols and Levy and Hollan's person-centered interviewing methods (Levy and Hollan 1998; Weiss 1997; Young and Kirmayer 1996). The resulting open-ended structure provided organization to the research encounter, yet retained enough flexibility to allow other salient issues to emerge.

Separately, I conducted a survey of the general public orally with pedestrians on the streets of a middle-class neighborhood, as well as employees at nearby businesses. The subjects included 30 men and 30 women, ages 18-60.

\section{Results}

Between January 1, 2003, and June 30, 2005, what would be diagnosed as bipolar disorder in the United States (including bipolar I, bipolar II, and unipolar mania) represented $21.0 \%$ of the inpatient diagnoses at Kangning Hospital $(n=4,461)$. Schizophrenia and unipolar depression composed 46.1 and $4.7 \%$ of the inpatient diagnoses, respectively. Records for outpatient diagnoses were not available.

None of the patients or family members I interviewed had heard of bipolar disorder prior to the patient's diagnosis. Among the 60 members of the general public I interviewed, bipolar disorder was the least-known psychiatric term, ${ }^{4}$ followed by manic-depression, depression, and schizophrenia (see Table 1). Since bipolar disorder was not a concept of popular knowledge, there was no sense of "bipolar identity" (Lakoff 2005) among the patients, and no shared master narrative of how 'bipolar disorder' should unfold as an entity among the patients and their family members.

Many elements of patients' descriptions of their experience corroborated with Western diagnostic criteria for bipolar disorder. Those that resonated with mania included increased talkativeness, rapid thoughts, sleeplessness, sociability, euphoria and feelings of capability; those that evoke depression included fatigue, lack of interest, feelings of low self-esteem and suicidal ideation in some cases. Headaches and dizziness surrounding and during episodes of illness are common complaints, but it was often unclear whether these bodily symptoms were associated with depression, mania, both or effects of medication.

All patients and family members had taken some form of action to avoid perceived stigma (such as hiding the diagnosis from relatives, friends or coworkers). Almost all patients initially approached mental health care due to coercion from

\footnotetext{
${ }^{4}$ The only person surveyed who had a basic understanding that 'bipolar disorder' was a psychiatric disorder involving moods was a man who had previously been diagnosed with it himself.
} 
family members. Family members were often notified and advised to seek help at Kangning Hospital by the patient's employer. Six patients visited traditional Chinese medical doctors prior to or following their visit to Kangning Hospital, and seven visited doctors of various specialties other than psychiatry prior to seeking help at Kangning. Patient and family perspectives on the meanings and implications of illness were heterogeneous.

Here, I focus on one pattern that emerged with regard to generationality and experience. Among my interviewees, narratives of individual responsibility and self-blame for illness control were prominent among patients of the post-Mao generation (those who grew up in the post-1980s economic reform era in China), while such narratives were almost absent in patients who reached their adolescence during the Maoist era.

Patients who privileged the self as the agent that ought to control the illness constituted four of five in the 18-25 age range (those born into the reform era), two of four in the 26-35 age range (those who spent their childhood and/or adolescence during the transition into the reform era) and one out of six in the 36-58 age range (those who spent their childhood and/or adolescence in the Maoist era) (see Table 2). While these numbers lend themselves to a gradated rather than a dichotomous categorization, I find the term generation more useful than the term age in writing about this particular difference in illness experience, as it helps maintain the conceptual link between this difference and China's cultural-historical changes, discussed below. And although the categories of 'self' and 'nonself' (as used in Table 2) are admittedly crude, since the contents and boundaries of selfhood often vary across and even within cultural contexts (Hsu 1985; Markus and Kitayama 1991), I use these terms as heuristic here to draw out the shifting notions of agency that deserve more refined investigation in the future.

I illustrate the texture of this pattern by examining four individual cases. I chose these four patients because the elements of their experience related to issues of control, agency and responsibility reflect those of their generational cohort. I first introduce two patients who reached their adolescence during the Maoist era, followed by two patients who were born in the post-Mao reform era. Pseudonyms are used to protect the interviewees' identities.

\section{Could It Be Madness-This? ${ }^{5}$ Four Stories}

Mr. Tian

Mr. Tian is a 57-year-old retired government employee from Northeast China. He was interviewed along with his wife-a 56-year-old retired schoolteacher-at Kangning Hospital's inpatient ward. Two years prior to the interview, Mrs. Tian had noticed Mr. Tian's increasingly bad moods. At the time, she thought that her husband was undergoing a midlife crisis and "growing a temper" due to his age. Roughly 20 days prior to the interview, Mrs. Tian decided the problem was

\footnotetext{
${ }^{5}$ Subtitle inspired by Kay Jamison's (1993) quotation of Emily Dickinson.
} 


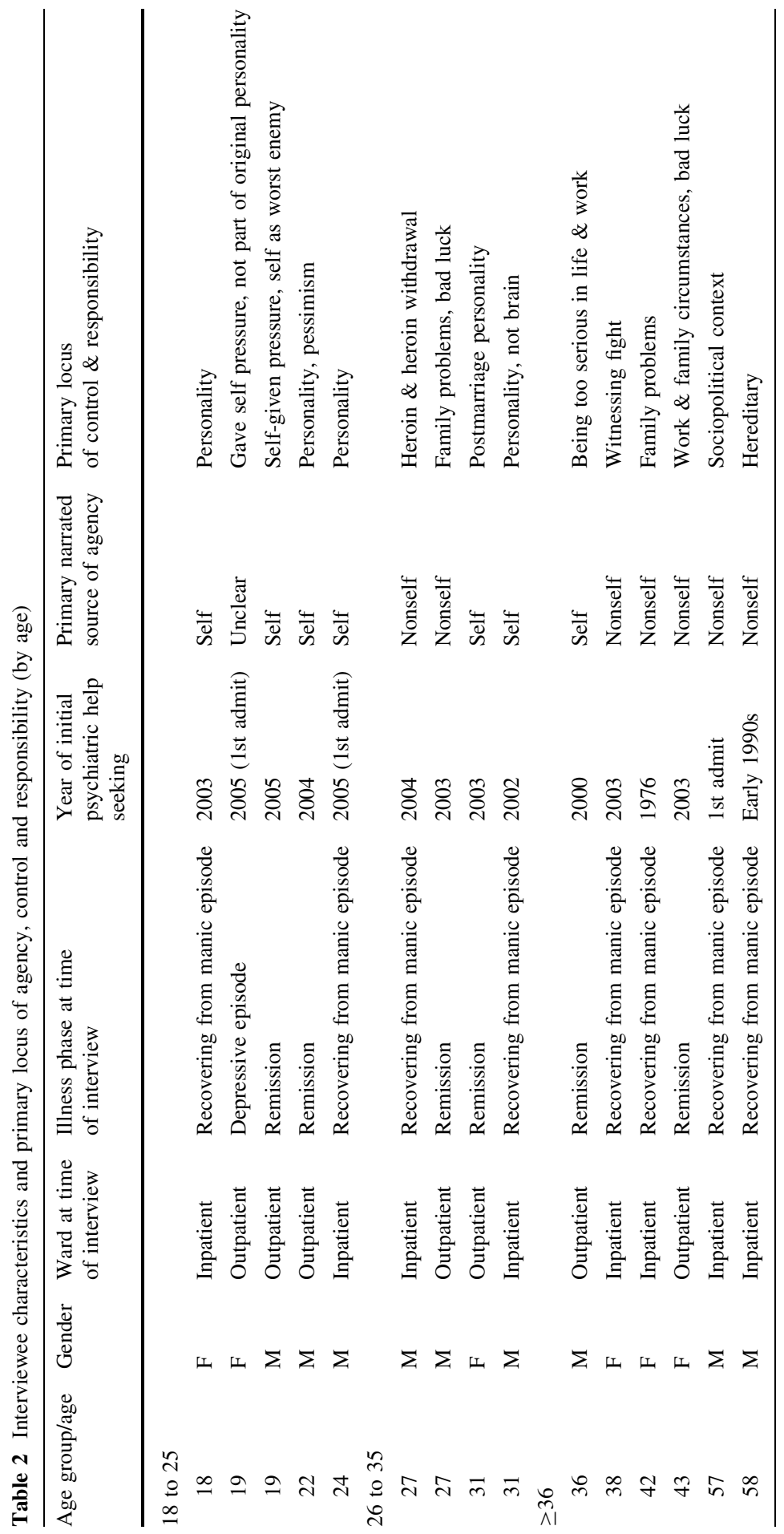


pathological, since Mr. Tian began to get "fired up" (fahuo; literally, to emit fire) without apparent justification, take anger out on anyone who came into contact with him, grow restless when playing mahjongg with friends and "speak senselessly" (luanshuohua) with no reason or order. Mr. Tian was then "tricked" into Kangning Hospital for treatment.

Mr. Tian did not agree with Mrs. Tian's assessment of the situation. He felt that his speech was not entirely nonsensical; it was merely tangential in structure. He explained that he had appropriate reasons for being irascible, because the matters troubling him were worthy of getting "fired up" about in and of themselves, "regardless of [his] ill state-or what others consider to be an ill state." These troubles consisted primarily of work worries, particularly regarding the younger generation of employees who did not seem to care about the fate of Mr. Tian's work unit, unlike workers of the older generation. He noted that the unsatisfactory circumstance was not due to his "personal issue" or lack of effort. Instead, it was a result of national policy changes that "do not allow you to fix" the situation and "necessarily causes collapse; necessarily causes you to collapse." Mr. Tian often challenged others' label of his behaviors and feelings as "ill," yet he did describe his current situation as an "outbreak of illness." He felt that a combination of longterm and short-term factors caused the outbreak. The long-term factors entailed worries about the work unit and national policies. The short-term factors involved an angry confrontation with a younger brother and days of sleeplessness due to visits with hometown friends at his father's funeral 20 days prior to the interview.

Mrs. Tian expressed great worry and anxiety that Mr. Tian would get severely ill in the future. She was concerned about how she would face him if he were to become fengfengdiandian (a term for stereotyping the behavior of those considered insane involving reduplication of two characters for 'crazy'). She noted that Mr. Tian's mother had also exhibited signs of being fengfengdiandian in the past and wondered if the illness was hereditable. Mr. Tian objected to the idea that his mother had an illness and chuckled dubiously at the idea that he would get ill again in the future.

\section{Ms. Shan}

Ms. Shan is a 43-year-old public sector administrative manager in a human resources department. She grew up in Sichuan province and was assigned to Shenzhen for work when she graduated college in 1982. Describing the first time she got ill, Ms. Shan spoke about national policy changes that led to structural changes at her work unit. The changes left her with inadequate staff support, which then increased her workload, heightened her job pressure and disrupted proper rest. Concurrently, her ex-husband (to whom she was married at the time) was having business troubles, her only daughter was having school problems and her younger sister was quarreling with her. The sum of these problems became very hard for Ms. Shan to withstand-she felt like the "sky was going to fall" and wondered how she could be so unfortunate (daomei).

Ms. Shan identified the day she got ill as the day she suddenly began "speaking nonsense" (luanshuohua). She said that her speech was logical and her brain was 
particularly lucid. She could go on for days without sleep and felt particularly intelligent and imaginative. However, she felt she could not control her behaviors. She felt suspicious of people and household objects. She turned statues in her house to face away from her. She smashed her cell phone because she thought her husband was intentionally disrupting her phone connection. She pounded on the door angrily when she thought her husband was trying to lock her out. She said "heartless" things to her daughter and sometimes hit her. Ms. Shan's family and coworkers began suggesting that she visit a doctor. She felt that she did not have an illness and was annoyed at others' coaxing.

A few months after the coaxing began, Ms. Shan's younger sister, brother-in-law and husband drove her to Kangning Hospital. "The moment I saw it was a hospital I started yelling to death: You all go yourselves! I don't have an illness!" Ms. Shan recalled. At the outpatient ward, a psychiatrist injected Ms. Shan with tranquilizers, and she went home to sleep for 2 days straight. After this initial visit, Ms. Shan began feeling discomfort again and went to a Chinese medicine doctor. She felt that the Chinese medicine did not improve her condition and made her drowsy. She continued to work despite extreme fatigue and was brought back to Kangning Hospital a year later, this time willingly. She was hospitalized for a manic episode. She described the behaviors and feelings leading to the second visit to Kangning Hospital as similar to those preceding her first visit. She was suspicious toward her family and felt she could not contain the need to fazuo (in medical terms this refers to an episode of illness; in common speech it refers to a sudden break out, particularly of an angry fit). She felt like a "tea kettle that needed to let out its steam."

Upon returning home after a month and a half of hospitalization, Ms. Shan found out that her husband was chatting online with other women. Speaking about this during the interview, Ms. Shan began to sob lightly. She felt that her husband was being very unfair to her, since she could not avoid getting ill. Her husband filed for divorce 6 months after her return, then moved to his hometown with their daughter.

Ms. Shan said that she has become more optimistic about the situation since then. She has decided to take life "one step at a time." At the time of the interview, she had not had any more relapses and said that she was taking her medication consistently. "It is like myopia, except you cannot take the glasses off," she said of her illness. Ms. Shan said that she could not figure out why she got this illness; it seemed strange and out of the blue (momingqimiao). She did not know why she was so unfortunate (daomei). "There is nothing to do about it. Nobody is willing to get this illness."

Mr. Lu

Mr. Lu is a 19-year-old first-year undergraduate biochemistry student whose parents own a plastic manufacturing factory in Shenzhen. On the day of the interview, Mr. Lu was accompanied by his mother to the Kangning Hospital outpatient clinic for his biweekly checkup. Mr. Lu's mother noticed something different about her son in April 2005. After expressing a feeling of fatigue (kun) several times, her son announced that he no longer wanted to "force himself" to attend school. Mr. Lu's 
mother was very worried and took him to a Chinese medicine ward to have his liver examined, to an internal medicine ward to have his brain examined and to another Chinese medicine ward recommended by a friend. None of these three visits provided satisfactory explanations for Mr. Lu's condition, although he was tentatively diagnosed with depression. Doctors at the latter two institutions prescribed Prozac for Mr. Lu (marketed in China under the name baiyoujie; literally, "free from a hundred worries"), and the doctor at the last of the three hospitals recommended a visit to Kangning Hospital. At the Kangning outpatient ward, the attending psychiatrist increased Mr. Lu's Prozac dosage. Soon, Mr. Lu's mother began noticing that Mr. Lu was growing unusually excited. Within a week, she forced him back to Kangning Hospital, where he was hospitalized for the first time for what was labeled a manic episode.

Mr. Lu had also noticed changes in his feelings and behaviors but did not wish to be "restrained" in the hospital. He said that his "personality changed entirely" - he felt more active, passionate, confident, social and intellectually curious. His body felt healthy. He stayed up at night to chat with friends, audited extra university courses, spent more money shopping and felt there were many things to do and little time to do them.

Prior to his first visit to Kangning Hospital, Mr. Lu did not believe he had a psychological or physical illness. However, by the time of the interview, Mr. Lu felt that all the experiences described above could be considered an illness. In fact, he had been reading about mood disorders on the Internet and in the psychology books he purchased. He believed that pressure from school was the main cause of his illness. "Even though no one gave me pressure, I gave myself a lot of pressure. I always thought about how I could improve myself.... I did not feel I could do anything well," he said. "I need to face myself. I am my own worst enemy.... I need to break my own boundaries."

\section{Mr. Zhong}

Mr. Zhong is a 24-year-old laborer at a battery manufacturing factory. Originally from a rural area in Henan province, Mr. Zhong moved to Shenzhen in 2000 after being recruited from his hometown. He felt that Shenzhen was a suitable place for young people to venture and discover better work prospects. At the time of the interview, he had been in Kangning Hospital's inpatient ward for slightly over a month. When describing what the psychiatrists later diagnosed as a manic episode, Mr. Zhong explained that he felt "very normal" at first, albeit more energetic than usual. He had felt very "mighty and glorious" at the time, and believed that he had important missions to accomplish that were sent from higher heavenly powers. During this period, Mr. Zhong's coworkers and supervisor deemed his behavior to be "abnormal," and his supervisor contacted Mr. Zhong's parents (who were farmers in Henan) to inform them that he needed to be taken to a psychiatric hospital. Mr. Zhong was unsure why others took notice of his behavior ("You would have to ask them"), but said that he did not protest the hospitalization, as he trusted that his father would only do what was right for him, and felt that others "should be 
correct" in their judgment of his behavior as abnormal, since he was "speaking from the perspective of the patient."

Prior to hospitalization, Mr. Zhong felt depressed because issues of career and love were perplexing him. "[Work] competition is intense. If you are not performing well today, tomorrow someone will chase to your level. And this causes a feeling of competition, a feeling that you cannot stop [moving forward]." Similarly, he felt "pressure" from the realm of love: "If you do not do well today, tomorrow [she] will become someone else's girlfriend. This creates a feeling of competition."6

Mr. Zhong felt that the cause of his illness was "inseparable from [his] own personality," as he was someone who was always striving (fendou). He said that his personality had led him to the point of illness, and that "if one is ready to strive intensely for a career, pursuing the highest goals, the striving might be accompanied by the development of illness." He also felt that illness was related to the "method" (fangfa) with which one deals with life matters. "If you know how to use your brain (tounao) to do things, it is not possible that this illness would develop... Because if you use method to do things, you can use your brain separately. You can direct your thoughts.... At that time, I did not pay attention to method."

Mr. Zhong worried that he would have a difficult time finding a girlfriend once he returned to his hometown. "When they hear that you have this illness, who would be willing to marry a psychiatric patient?" The only people that were informed about his illness were his immediate family and supervisor. Mr. Zhong was uncertain whether the factory would allow him to keep working-" because I am a psychiatric patient." In fact, the factory would not have paid for Mr. Zhong's hospitalization if Mr. Zhong's father had not insisted on his behalf. "My dad is over 50 years old, and is still worrying about these things for me. [Sighs] As a son... I feel I owe (my parents) so much."

\section{Rise of the Individual: Control and Responsibility in Contemporary China}

Past works in anthropology and psychology have described the Han Chinese orientation toward life and illness as situation-centered with an external locus of control rather than individual-centered with an internal locus of control, as found in the dominant Protestant-influenced culture in the United States (Hsieh et al. 1969; Hsu 1949, 1971; Kuo et al. 1979). Applying this concept to his initial ethnographic study of depression in Chinese populations, Kleinman (1982, p. 149) wrote, "A peculiar type of displacement of dysphoric affect among the Chinese is the tendency to shift concern from the affect itself to the concrete situation that generated or is maintaining the affect."

Reform-era sociopolitical changes have been impacting these cultural orientations. In his ethnography, Yan (2003) documents gradual national and local processes that

\footnotetext{
${ }^{6}$ In Shenzhen - and much of China - at the time of the interview, there was a popular notion that women prioritize a man's wealth when seeking a potential partner. The economic component makes the parallel between competition in work and romance even more pronounced.
} 
have led to the rise of the individual in the post-Mao generation. Yan argues that Chinese Communist Party land reforms and collectivization policies of the 1950s caused shifts of loyalty from the family to the state. After the collapse of collectivism, the lack of traditional or socialist moralities created a vacuum that was filled by the capitalistic values of reform era. These series of transitions seemed to have fostered the new Chinese emphasis on the individual in certain contexts.

The growing import of the individual has also been documented in psychology. In a review of psychological studies on motivational characteristics, evaluativeattitudinal characteristics and temperamental characteristics in Taiwan, Hong Kong and mainland China, Kuo-Shu Yang (1996) compiles a hefty list of decreasing and increasing psychological characteristics of Chinese individuals under the impact of what Yang terms "modernization." Among the characteristics decreasing with modernization are external-control beliefs, fatalistic-helplessness attitudes, collectivist relationships, emphasis on social service, emphasis on national development and social-oriented achievement. Characteristics increasing with modernization include internal-control beliefs, self-assertion, competitive attitudes, individualistic consciousness, autonomy and individual-oriented achievement.

Studies in the workplace corroborate the ethnographic and psychological evidence. One study found that employees in China are placing increasing priority on their desire for wealth and a happy family and decreasing value on contributions to the nation and community (Hui and Chen 1996). A survey of 869 professionals from regions across China found that the generation of managers who spent their adolescence in the reform era-popularly dubbed the "Chinese Me Generation"was significantly more individualistic, less collectivistic and less committed to Confucian values than those who grew up in the Maoist era (Ralston et al. 1999). In sum, the lifeworlds of individuals who grew up in the post-Mao era differ considerably from those of the generation before them, and cognitive and experiential orientations are changing with the cultural rise of the individual.

\section{Heartache of the State, Enemy of the Self: Intergeneral Shifts in the Meaning of Bipolar Disorder}

While Kleinman's ethnographic works showed that Chinese individuals tend to express their illness in terms of concrete situations in their sociomoral world, my interviews suggest a shift in this cultural pattern. The cases presented above suggest that while those who grew up in the Maoist era-such as Mr. Tian and Ms. Shanare inclined to describe their illness experience through situational models, the postMao generation-represented here by Mr. Lu and Mr. Xiong-veer away from this sociomoral approach.

Mr. Tian described the source of his illness as the combination of long-term changes in his work unit and the recent events at his father's funeral. Even though he used the term "illness" to describe his experience at times, Mr. Tian repeatedly questioned this label and emphasized that the matters troubling him were not a reflection of "personal" problems. He felt that his fiery anger, which the psychiatrist labeled as a manic episode, was a justified reaction to failed state policies. Mr. Tian's 
criticism of the national changes that will lead to "collapse" metaphorically connects the sociomoral world to his ill body. While he first referred to a collapse in public infrastructure, he added, importantly, that it "necessarily makes you collapse" (feiyaorangnidao). In Chinese, this is translated verbatim as "must-want-let/makeyou-collapse." This discursively imbues the state with intention (want) and agency (let/make). Through these parallel phrases, Mr. Tian suggests that what others are insisting to be his "illness" is actually a broader problem created by the state, befallen on both society and his body. His descriptions of short-term sleeplessness and a burst of anger at the funeral fit well within a traditional Chinese medical framework. Lack of rest and excessive expressions of emotion are both viewed in Chinese medicine as harmful to the body and capable of causing illness (Kleinman 1980; Wu 1982). Between the policy changes and the funeral, Mr. Tian was able to explain his purported illness in terms of circumstantial causation.

Like Mr. Tian, Ms. Shan cited numerous events in her life involving national policy, work and family that provoked disruption of rest, anger and extended worry. However, she referred to bad fortune rather than specifying a primary agent of responsibility to account for her unusual emotions and behavior. Ms. Shan did not emphasize the role of morality or intention in either the cause of her illness or the moods and behaviors. Although her comment about lack of staff support at work and her suspicions toward her husband and family during her illness could be interpreted as indirect moral commentary about sources of injustice, it must be pointed out that Ms. Shan herself did not explicitly make such connections. Instead, she highlighted the element of uncontrollability in both the unexpected occurrence of the illness (momingqimiao, which is a common idiom denoting a baffling and unaccountable event, translating roughly to "a wonder without a context") and her subjective affective experience (the metaphor of the uncontainable steaming kettle). The linguistic focus on lack of control embeds the illness in a situational context of misfortune sans injustice or intention. Ms. Shan's story of bad luck thus differs from Mr. Tian's account of a moral emotional reaction to immoral circumstance. However, their narratives share two common elements-the elaboration of significant life situations surrounding the illness and the lack of self-blame.

The situational focus takes on a diminished role in Mr. Lu's narrative. Although he cited pressures from school and everyday life as triggers of his illness, the story of the illness centered on him as the primary problem-inducing agent. Mr. Lu's verbal refusal to "force himself" to attend school incited a series of help-seeking attempts. Thus, the problem was publicized as a form of dissonance within the self from the start. "School" as a circumstantial entity sinks into the background when Mr. Lu's battle with his own conflicting feelings rises to the foreground. His comment that "no one gave [him] pressure" except himself shows an underlying assumption that "pressure" is a source of distress to be generated by individual action. In contrast to Ms. Shan's unfortunate, situational life pressures, Mr. Lu's school pressure is something he "gives" himself through "thought" of selfimprovement. Most strikingly, Mr. Lu described himself as his "own worst enemy." This attributes not only the source of illness but also the responsibility for healing to the individual. The images of "facing" the self and "boundaries" within the self denote an inner fragmentation. Rather than a relationship between the problematic 
society and the moral body (as in Mr. Shan's case), the divergence and struggle portrayed in Mr. Lu's narrative are located within his own psyche. His source of hope, then, lies in the defeat of an undesirable part of himself.

Finally, similarly to Mr. Lu, Mr. Zhong spoke of his illness as ultimately a problem of control within the self. While he described the contexts of romantic and work competition as a source of "depressed" feelings, he did not seem to implicate these circumstances when locating agency for the cause of his "illness" per se (see discussion above on the common nonpathological feelings of depression; Psychiatry and Depression after Reform), or when discussing the potential for change in the future. Instead, he narrated his illness as a natural product of his "striving" personality that was prone to illness, in conjunction with his failure to "use method" and "direct" his thoughts in order to interfere with these characteristics. Unlike Mr. Tian, who insisted that the root of the problem was not personal, Mr. Zhong described just the opposite. In fact, the problem was personal for Mr. Zhong in two ways: both in his "personality" and in his inability to control it.

These four cases illustrate that "bipolar disorder" do not implicate the same notions of responsibility, control and blame across the younger and older patients. While I am emphasizing the contrast between the generations, it is important to note that many of the patients I interviewed entertained multiple possibilities for explaining and narrating their illness experiences. Overall, there was more variation in the causal explanations among the older generation, including narratives of family conflict (e.g., "the main reason [I got ill] is my maternal grandmother. No matter how good I am to her... she just had to bully me like that"), a startling event ("I saw people fighting across the street from my shop.... I got scared.... I lost my appetite and could not sleep") and one of inheritance and misfortune ("This illness is somewhat passed down through the family ... my father, paternal uncle, and paternal aunt all had this illness... I feel very unlucky.... I have so many siblings. It did not happen to any of them, but it happened to me").

Despite the variation, one commonality is that the emphasis on self-blame and individual responsibility for control was absent in most of the older generation's narratives, whereas it was remarkably salient among the younger generation. This was reflected in both causal statements about the past (e.g., "Studying-related pressures [caused this illness].... I wanted to study in the highest-ranking class, so I studied incessantly. At last, I could not escape myself") as well as statements regarding future responsibility (e.g., "[My depression] is hard to get out of. I must step-by-step, slowly adjust myself, rely on myself.... You can only rely on yourself to adjust your mood").

\section{Contextualizing Distress: To Live and Work Across Reform}

To better understand the four interviewees' narratives of distress sketched above, it might be helpful to note the changing relationships between individuals and work in China across the decades. Major structural changes to the workplace in the reform era have led to increased flexibility and mobility for both employers and employees, in contrast with the stability and rigidity of Maoist-era work units (danwei). For 
workers of the Maoist era, one's work unit was not individually chosen, and it defined one's identity for all legal and bureaucratic purposes, as well as many aspects of one's social life (Bray 2005). Although some may not have been too satisfied with their allocations, the posts were seen as "iron rice bowls" one could count on, usually for life. Thus, the relationship to the workplace was one of restraint, yet also one of reliability and support. The obligation was mutual.

The transition toward a market economy in the reform era has seen the dismantling of this model. While the work unit still exists, its reaches have been diminished due to the increasing influence of privatization. Workers and employers can now choose one another as well as dismiss one another, particularly in the private sector. Fewer promises are made from both ends. This has led to a related shift of attitude in younger workers, who prioritize the well-being of their personal and (often nuclear) family lives over that of the greater community and workplace (Hui and Chen 1996). In this context, Mr. Tian's narrative of frustration toward national policies and younger employees can be seen as a response to the changes in both workplace structure and worker psychology in the post-Mao era.

For those who have not yet retired, but began their careers in a time of more stable work unit structures, such as Ms. Shan, increasing economic pressures on the public sector from new market competition and shifting government allocations have led to often unexpected changes in work arrangement. For instance, shifts since the 1990s toward a neoliberal model of diversified funding sources have led to many reductions or outright termination of pension benefits, leaving some older workers and retirees nostalgic and bitter about promises made in the Maoist past. Across the country, workers and retirees have organized public protests over the depletion or denial of benefits (Frazier 2004; Hurst and O'Brien 2002).

For those entering the labor market after economic reforms, one's relationship to the workplace is one of temporal and structural mutability. Workers of the reform era are faced with more options, as well as more stresses of market competition. Lacking reliable safety nets in the socioeconomic domain, many younger workers and students such as Mr. Zhong and Mr. Lu feel that they must indeed 'rely on themselves' for their own welfare and livelihood, as the availability of employment and benefits remains in constant flux, particularly for migrant laborers like Mr. Zhong (Wong et al. 2006). Thus, while the four patients' interview narratives ${ }^{7}$ are being used here to examine the intergenerational orientations toward the experience of bipolar disorder, it is important to recognize that the contents of their complaints are very much in step with the socioeconomic atmosphere of their times.

\section{Culture, Self and Agency: The Question of Implications}

Implications for the generational shift toward individual control and responsibility can be examined from multiple, sometimes paradoxical angles. Here,

\footnotetext{
7 These are not to be confused with the speech that initially led family members and coworkers to identify them as 'abnormal,' since these interviewees were in much more stable condition by the time of my interviews.
} 
I discuss potential trajectories of impact from psychological and anthropological perspectives.

From the psychological perspective, the growing prioritization of personal agency can have potential effects on multiple domains including treatment compliance, mood cycles, overall psychological health, self-esteem and self-stigma, but the directions of impact are difficult to delineate. Studies on the relationship between control and overall psychological health in Chinese populations have shown mixed results. While some studies of Chinese individuals have found correlations between negative psychological impacts and an internal orientation toward illness attribution (Crittenden 1996), others have found an external locus of control to be associated with poor psychological health (Leung 1996). This might point to the complex interaction between psychological well-being and cultural norms, discussed below.

Research on how locus of control affects treatment compliance (including medical adherence and clinical visits) in bipolar patients remains scarce. The health locus of control framework was originally grounded in the concept that an internal locus of control would lead to improved treatment adherence and other health behaviors (Wallston and Wallston 1978). However, the few studies available cast doubt on the applicability of this assumption to bipolar disorder. One literature review on controlled trials of treatment adherence enhancement did not find a clear influence of locus of control (Sajatovic et al. 2004). A British study of lithium treatment in bipolar patients not included in this review found that an internal locus of control did not improve treatment adherence (Harvey and Peet 1991). Another British study of outpatient bipolar and schizophrenic patients on long-term pharmacotherapy found that high treatment adherence was in fact associated with external loci of control for the illness, particularly the belief that the illness was controlled by chance happenings (Adams and Scott 2000).

My interviews also suggest that the dominant Western tendency (or the one most often cited in generalizations of 'the West') to presume the desirability of an internal locus of control for health behaviors (Rotter 1975) is problematic. Although the younger Chinese patients I interviewed located agency and responsibility within the self, this "self" is largely characterological rather than the "neurochemical selfhood" (Rose 2003) imagined by many U.S. bipolar patients, for whom "the belief that the brain and its genetic determinants lie behind mental disorders like manic depression was simply assumed" (Martin 2007, p. 11). Mr. Lu, who considered his personality gupi (an eccentric, often uncommunicative disposition), gives us a clue about the potential significance of this characterological belief for medical adherence: "[This illness] is not something that can be cured by seeing a doctor for a few weeks. One must think about slowly getting better. The medicine might have some [positive] effects, but the most important thing is relying on oneself... Medicine can only have a small portion of effects."

Unlike Martin's subjects, for Mr. Lu, seeing his illness as an individual problem does not then entail finding the right drug cocktail to fine-tune his neurochemical selfhood. Rather, his Chinese "individualistic" orientation resembles a prolonged struggle with a problematic personality that might be ameliorated temporarily, but not won, with the assistance of medication. This parallels a recent finding that the 
meaning of recovery among Chinese schizophrenic patients differs from that among patients in the West. Namely, Chinese patients diagnosed with schizophrenia believed that "full recovery could not be said to have been achieved until they stopped medication" ( $\mathrm{Ng}$ et al. 2008, p. 118). Ng and coworkers' participants ranged from age 36 to age 43 , which suggests that the rejection of medicated selfhood is present among older as well as younger Chinese psychiatric patients. Thus, further research is needed to sketch out more precise relationships between locus of control and treatment compliance in Chinese contexts.

As for the impact of control and attribution on moods, there are fewer data and theoretical frameworks available for discussing bipolar disorder than unipolar depression, thus I borrow from literature on unipolar depression here, despite the difference in phenomenological contexts and clinical presentations between bipolar and unipolar depression. The scarcity of psychosocial research on bipolar disorder might be due partly to the scholarly tendency to reduce bipolar disorder to a closed biological system rather than a dynamic biopsychosocial one (Floersch et al. 1997). For unipolar depression, the psychological theory of learned helplessness suggests that the perceived loss of personal control over dysphoric moods might lead to a cycle of cognitions and behaviors that reinforce depression (Peterson et al. 1993). A meta-analysis of external locus of control and depression has found that there is indeed a largely positive relationship between the two (Benassi et al. 1988); this relationship was also found in a study of depression among psychosis patients (Birchwood et al. 1993). If the causal relationship hypothesized by the learned helplessness theory is correct, these results suggest that the internal orientation toward control and responsibility in the post-Mao generation could potentially act as a moderator and help decrease depressive symptoms, while the older bipolar patients' circumstantial orientation could act as a mediator and increase them.

Interestingly, there is a flip side to learned helplessness - the tendency for selfblame in depressive patients. This has led some authors to speak of a "depressive paradox," the concurrent attributions of negative events to the self and the perception that matters are uncontrollable (Abramson and Sackheim 1977). Yet, individual control in the form of self-blame has largely been framed in Western psychological discourse as a product of depression rather than a potential source. One study found a particularly high association between characterological blame and depressive symptoms (recall Mr. Zhong's "striving personality" and Mr. Lu's gupi character), but argues that it is not a causal relationship (Peterson et al. 1981). A refinement of concepts and examination of potential cultural biases would facilitate a more thorough understanding of the relationships between control and affect in depression as well as bipolar disorder. ${ }^{8}$

Aside from potential impacts on mood cycles, an individual orientation toward responsibility can also affect self-concept. In an attempt to construct a heuristic social psychological model for understanding the relationships among self-stigma, self-esteem and self-efficacy in individuals with mental illness, Corrigan and

\footnotetext{
${ }^{8}$ Weems and Silverman (2006) have made a formidable attempt to formulate a model of control, emotion regulation and anxiety, but an in-depth discussion of its implications for bipolar disorder in Chinese individuals is beyond the scope of this paper.
} 
Watson (2002) touch on two ideas relevant to the present discussion: (1) the internal attribution of negative feedback has been linked to low self-esteem in past research; and (2) the sociopolitical ideology of the Protestant work ethic-summarized there as the concept that "an individual's hard work is the foundation of success; lack of success indicates the person's self-indulgence and poor self-discipline" (p. 41)-has been found to have a negative impact on stigma-related self-esteem in some stigmatized groups in the West. These findings suggest that internal attribution of the failure to prevent illness can have deleterious effects on self-esteem and selfstigma in those diagnosed with mental disorders and stigmatized groups. While this hints at potential risks of the post-Mao generation's perceptions of personal agency in bipolar disorder, Corrigan and Watson emphasize that "the impact between selfattributions of responsibility for mental illness ... and self-stigma remains to be tested" (p. 47), and that there are numerous factors such as perceived legitimacy of stigma, in-group identification, and specific characteristics of the diagnosis that can mediate, moderate and complicate the relationships.

Of course, we must keep in mind that the psychological models discussed above were born of a Euro-American intellectual context where individualistic values have been core to ideals of personhood historically, whereas in China, psychosocial homeostasis has been prioritized (Hsu 1971) up until recent cultural changes. In fact, some have suggested that using the individual as the basic unit of analysis is problematic in studying Chinese populations, for whom methodological relationalism and person-in-relations are more appropriate starting points (Ho 1991; Ho and Chiu 1998), as the Chinese concept of personhood is inherently social, unlike the Western notions of personality (Hsu 1985). However, as the results of the present study suggest, along with culture and economics, the Chinese notion of personhood is undergoing rapid change. Thus, both Western and traditional Chinese frameworks might be insufficient for dealing with the ethnopsychological constructs of the postMao generation(s). ${ }^{9}$ It seems that new models are needed to properly address-or catch up with - the speed of cultural change in contemporary China. In the meantime, we would do well to keep in mind that beyond psychological issues of control, "conformity with cultural ideologies of the person may be just as important as any specific attributional pattern for the psychic economy" (Kirmayer and Groleau 2001). In other words, the presence or absence of individual responsibility and self-blame in and of itself may hold less explanatory power for psychological implications than their feedback and interaction with the patients' interpersonal and cultural realities.

When the analytical lens is flipped toward the issue of power, social scientists have long critiqued the medicalization of sociomoral deviance and human suffering (Foucault 2006; Scheper-Hughes 1979). In his classic essay "Medicine as an Institution of Social Control," sociologist Irving Zola (1972) writes, "The labels health and illness are remarkable 'depoliticizers' of an issue. By locating the source and the treatment of problems in an individual, other levels of intervention are

\footnotetext{
9 Even the dichotomous construction of Maoist and post-Mao generations is problematic, as many younger Chinese I met during fieldwork noted a wide gap between the ' 80 s generation' (i.e., those born in the 1980s) and the '90s generation,' and often claimed-while shaking their head-that the two 'generations' are mutually incomprehensible to one another.
} 
effectively closed." The institutions, and more recently "assemblages" (Ong and Collier 2005), of the "psy disciplines" (Rose 1996) have been critiqued as an evermutating apparatus for governing the social subject, in some historical moments by external surveillance and control, while in others via internalized, normative, biopolitical and neoliberal discourses.

From this angle, the sociomoral idioms of distress documented by Kleinman can be viewed as a channel of discursive resistance in a time of extreme political sensitivity, whereas a slight irony can be tasted in the contemporary context, where decreased state regulation of individual social critique in post-Mao China (Link et al. 2002) has been accompanied by disciplinary mechanisms facilitating the internalization of what would have previously been viewed as social or circumstantial ills. Younger Chinese, while experiencing more freedom of political expression from an earlier age, might not be prioritizing this opportunity (Elegant 2007). Introducing a series of visual works by Chinese artists born in the 1980s, Schoeni (Cavero 2008) writes, "China's 'me' generation have ... a completely different set of values to that of the previous generation.... Successes and failures are increasingly taken as personal ones rather than corollary of relational and sociopolitical dynamics... Having been raised in a free market economy, politics is not of great concern to the "me' generation."

Recent anthropological theory of neoliberalism in contemporary China provides a framework for linking these personal experiences into broader modifications in human management. As Ong (2006, p. 3) summarizes,

A new mode of political optimization, neoliberalism-with a small $n$-is reconfiguring relationships between the governing and governed, power and knowledge, and sovereignty and territoriality ... governing activities are recast as nonpolitical and nonideological problems that need technical solutions.... Indeed, neoliberalism considered as a technology of government is a profoundly active way of rationalizing governing and self-governing in order to 'optimize.'

In such contexts of neoliberal subjectivity,

Disciplinary techniques and moralizing injunctions as to health, hygiene, and civility are no longer required; the project of responsible citizenship has been fused with individuals' projects for themselves. What began as a social norm here ends as a personal desire ... it has become possible to govern without governing society - to govern through the 'responsibilized' and 'educated' anxieties and aspirations of individuals and their families. (Rose 1999, p. 88)

So while the notion of individual agency is often viewed from neoliberal standpoints as a foundation for empowerment and a prerequisite for civic participation, it can also become a source of disempowerment when individuals decrease their expectations for social forms of responsibility. In short, while sociocultural changes of the reform era have opened up new spaces for discourse, tropes of individual responsibility and self-blame in younger bipolar patients' illness narratives may reflect and signify new forms of governmentality in which individuals participate in the legitimation of potential negative consequences of 
the emerging market economy. Life's hardships, including insecurities and inequalities traceable to new market-oriented systems of distribution, are redirected toward faulty personalities and insufficient individual efforts. The "heartache of the state" has become the "enemy of the self"- the self.

\section{Limitations}

The analysis presented here is limited to the small sample of individuals that I interviewed. The interviewees lived in Shenzhen, a young urban city where inmigration and sense of individual competition are particularly high, thus it is unclear whether and how the issues discussed apply in other settings across China. Also, the study was based at a Western-style psychiatric institution, which biases the sample to those who eventually utilize psychiatric services. Without extending the research to other sites such as general hospitals, traditional Chinese medical hospitals and the community, it is unclear whether the findings resonate with those who do not seek professional psychiatric help. Further ethnographic work is necessary for a deeper understanding of the issues intertwined, as the stories disclosed in the initial interviews might be impacted by lack of trust and fear of stigma. My own identity as a Chinese-American undergraduate from the United States also created a particular context for the interviews. Some patients may have chosen to avoid some topics knowing that I would not be of direct help in their treatment process. My age, ${ }^{10}$ gender and foreign-yet-Chinese qualities might have colored the ways in which they responded, depending on their perceptions of these factors. Finally, no clear-cut vector of causality can be drawn between broader sociocultural shifts and the apparent differences among the interviewees' responses. Nonetheless, the parallel between historical shifts in the cultural emphasis on individualism and cognitive foregrounding of personal agency in the younger patients' narratives of causality and responsibility is striking and deserves further exploration.

\section{Personhood in Flux: Bipolar Disorder and 'Chinese Culture'}

Post-Mao economic reforms and the influx of global capitalistic values are rapidly restructuring cultural norms and personal lives in China. The depoliticization of emotion, rise of the individual and entry of foreign pharmaceutical influences are redefining the way in which mental illness is experienced. While measures of national prosperity tell a story of success to the global audience, assessments of mental and social health are much less optimistic (Shenzhen Government 2006; Kleinman and Kleinman 1999). In this paper, I have suggested that, within the group of bipolar patients I interviewed, younger patients who grew up in the post-

\footnotetext{
${ }^{10}$ The potential influence of age (and gender) was made clear to me when one middle-aged male staff member said to me, "What kind of research can you do? What can you understand about human suffering if you have not yet endured the pain of childbirth?" I could not help but comment on the irony that he would in fact never have the chance to endure the pain he speaks of.
} 
Mao generation felt they ought to control their illness and often blamed themselves for its occurrence. Older patients did not usually blame themselves for their illness, but tended to refer to external circumstances or luck in their explanatory accounts.

The shift toward an individual-focused ethnopsychological orientation discussed above might be of concern in the context of new social ills accompanying the growing market economy. During the Maoist era, sociomoral idioms of distress provided a portal for discussion of social problems. The hypercognition of personal responsibility in the post-Mao generation might not only signify the replacement of a discourse that Chinese individuals have used to vocalize systematic injustice in the past, but also point to a new form of neoliberal self-governance that leads to the internalization of life problems. Potential psychological and clinical impacts of individual responsibility and self-blame discourses are multidimensional and remain to be unraveled. The intergenerational differences in the experience of bipolar disorder hints at impacts of sociopolitical changes on ethnopsychology, and raises questions about potential implications of psychological shifts for sociopolitical agency. Future studies and theories of mental illness and emotion in China must address the impacts and implications of cultural change in order to grapple with contemporary realities.

Acknowledgments I am immeasurably grateful toward my mentors Douglas Hollan and Robert Lemelson, who have been wellsprings of encouragement, inspiration, and wisdom. Their patient guidance and enduring support enabled me to realize this project. I am indebted to Cameron Hay-Rollins for her fruitful advice and insightful critiques, and to Veronica Pearson for her altruistic spirit that sprung this research into life. I am thankful of Nancy Levine, Richard Lesure, Jeanne Arnold, Yunxiang Yan, Candy Goodwin, Christopher Engelke, and Sing Lee for their help along this amateur academic journey. I would also like to thank the two anonymous reviewers whose comments were of great help in improving this paper. Words cannot capture my appreciation for all the interviewees and staff members I have met at Kangning Hospital. Of the mental health professionals, I would particularly like to thank Hu Jize, Hu Chiyi, Shen Qijie, and Fang Li for their warmth and support. This project would not have been possible without the generous financial support from donors to the Jesse Ingram Undergraduate Research Award, Rose Gilbert Scholars Program, Naumburg Summer Research Stipend, and Nadia Powers Scholarship Award.

Open Access This article is distributed under the terms of the Creative Commons Attribution Noncommercial License which permits any noncommercial use, distribution, and reproduction in any medium, provided the original author(s) and source are credited.

\section{References}

Abramson, Lyn Yvonne, and Harold A. Sackeim

1977 A Paradox in Depression: Uncontrollability and Self-blame. Psychology Bulletin 84: 838-851.

Adams, J., and Jan Scott

2000 Predicting Medication Adherence in Severe Mental Disorders. Acta Psychiatrica Scandinavica 101: 119-124.

Akiskal, Hagop S.

2002 Classification, Diagnosis and Boundaries of Bipolar Disorder: A Review. In Bipolar Disorder. Mario Maj, Hagop S. Akiskal, Juan Jose Lopez-Ibor, and Norman Sartorius, eds., pp. 1-52. Chichester, UK: John Wiley \& Sons.

American Psychiatric Association

2000 Diagnostic and Statistical Manual of Mental Disorders DSM-IV-TR. 4th Edition. (text revision). Washington, DC: American Psychiatric. 
Benassi, Victor A., Paul D. Sweeney, and Charles L. Dufour

1988 Is There a Relation between Locus of Control Orientation and Depression? Journal of Abnormal Psychology 97(3): 357-367.

Birchwood, Max, Robert Mason, F. MacMillan, and J. Healy

1993 Depression, Demoralization and Control over Psychotic Illness: A Comparison of Depressed and Non-depressed Patients with a Chronic Psychosis. Psychological Medicine 23(2): 387-395.

Bray, David

2005 Social Space and Governance in Urban China. Stanford, CA: Stanford University Press.

Burr, Vivian, and Trevor Butt

2001 Psychological Distress and Postmodern Thought. In Identity and Agency in Cultural Worlds. Dorothy Holland, Debra Skinner, William Lachicotte Jr., and Carole Cain, eds., pp. 186-206. Cambridge, MA: Harvard University Press.

Cannon, Terry, and Alan Jenkins, eds.

1990 The Geography of Contemporary China: The Impacts of Deng Xiaoping's Decade. New York: Routledge.

Cavero, Daniela, ed.

2008 Niubi Newbie Kids. Hong Kong: Schoeni Gallery.

Chen, Feng

1999 An Unfinished Battle in China: The Leftist Criticism of the Reform and the Third Thought Emancipation. China Quarterly 158: 447-467.

Chen, Hong

2005 Feeling the Pinch of a Growing Population, p. 3. China Daily, July 23.

Cheung, Peter

1991 Adult Psychiatric Epidemiology in China in the 80s. Culture, Medicine and Psychiatry 15: 479496.

Corrigan, Patrick W., and Amy C. Watson

2002 The Paradox of Self-Stigma and Mental Illness. Clinical Psychology: Science and Practice 9(1): 35-53.

Crittenden, Kathleen S.

1996 Causal Attribution Processes among the Chinese. In The Handbook of Chinese Psychology. Michael Harris Bond, ed., pp. 263-279. New York: Oxford University Press.

Davis, Deborah S.

1995 Introduction: Urban China. In Urban Spaces in Contemporary China. Deborah S. Davis, Richard Kraus, Barry Naughton, and Elizabeth J. Perry, eds., pp. 1-27. Cambridge: Cambridge University Press.

Deng, Zhenlai

2001 Drug Trafficking and Consumption in China: Two Case Studies. International Social Science Journal 53(3): 415-420.

Elegant, Simon

2007 China's Me Generation. Time Magazine Online. Available at: http://www.time.com/ time/magazine/article/0,9171,1647228,00.html. Accessed December 31, 2008.

Fairbank, John King, and Merle Goldman

1998 China: A New History. Cambridge, MA: Harvard University Press.

Feng, Jicai

1996 Ten Years of Madness: Oral Histories of China's Cultural Revolution. San Francisco: China Books and Periodicals.

Floersch, Jerry, Jeffrey Longhofer, and Kristine Latta

1997 Writing Amish Culture into Genes: Biological Reductionism in a Study of Manic Depression. Culture, Medicine and Psychiatry 21: 137-159.

Foucault, Michel

2006 History of Madness. Jean Khalfa and Jonathan Murphy, trans. New York: Routledge. (Originally published in 1961).

Frazier, Mark W.

2004 China's Pension Reform and Its Discontents. China Journal 51: 97-114.

Goldman, Merle

1998 The Post-Mao Reform Era. In China: A New History. John King Fairbank and Merle Goldman, eds., pp. 406-450. Cambridge, MA: Harvard University Press. 
Harvey, Norman S., and Malcolm Peet

1991 Lithium Maintenance: 2 Effects of Personality and Attitude on Health Information Acquisition and Compliance. British Journal of Psychiatry 158: 200-204.

Ho, David Yau-Fai

1991 Relational Orientation and Methodological Relationalism. Bulletin of the Hong Kong Psychological Society 26-27: 81-95.

Ho, David Yau-Fai, and Chi-Yue Chiu

1998 Collective Representations as a Metaconstruct: An Analysis Based on Methodological Relationalism. Culture and Psychology 4(3): 349-369.

Hsieh, T'sang-T'ang, J. Shybut, and Erwin J. Lotsof

1969 Internal versus External Control and Ethnic Group Membership: A Cross-cultural Comparison. Journal of Consulting and Clinical Psychology 33: 122-124.

Hsu, Francis L.K.

1949 Suppression versus Repression: A Limited Psychological Interpretation of Four Cultures. Psychiatry 12(3): 223-242.

1971 Psychosocial Homeostasis and Jen: Conceptual Tools for Advancing Psychological Anthropology. American Anthropologist 73(1): 23-44.

1985 The Self in Cross-cultural Perspective. In Culture and Self: Asian and Western Perspectives. Anthony J. Marsella, George DeVos, and Francis L.K. Hsu, eds., pp. 24-55. New York: Tavistock.

Hui, Harry C., and Tan K. Chen

1996 Employee Motivation and Attitudes in the Chinese Workforce. In The Handbook of Chinese Psychology. Michael Harris Bond, ed., pp. 364-378. New York: Oxford University Press.

Hurst, William, and Kevin J. O'Brien

2002 China's Contentious Pensioners. China Quarterly 170: 345-360.

Hwang, Kwang-Kuo

2000 Chinese Relationalism: Theoretical Construction and Methodological Considerations. Journal for the Theory of Social Behaviour 30(2): 155-178.

Jamison, Kay Refield

1993 Touched with Fire: Manic Depressive Illness and the Artistic Temperament. New York: Free Press.

Jenkins, Janice H., and Robert Barrett, eds.

2004 Schizophrenia, Culture, and Subjectivity: The Edge of Experience. New York: Cambridge University Press.

Kessler, Ronald C., Patricia Berglund, Olga Demler, Robert Jin, Kathleen R. Merikangas, and Ellen E. Walters

2005a Lifetime Prevalence and Age-of-Onset Distributions of DSM-IV Disorders in the National Comorbidity Survey Replication. Archives of General Psychiatry 62: 593-602.

Kessler, Ronald C., Wai Tat Chiu, Olga Demler, and Ellen E. Walters

2005b Prevalence, Severity, and Comorbidity of 12-Month DSM-IV Disorders in the National Comorbidity Survey Replication. Archives of General Psychiatry 62: 617-627.

Kirmayer, Laurence, and Danielle Groleau

2001 Affective Disorders in Cultural Context. Psychiatric Clinics of North America 24(3): 465-478.

Kleinman, Arthur

1980 Patients and Healers in the Context of Culture: An Exploration of the Borderlands between Anthropology, Medicine, and Psychiatry. Berkeley: University of California Press.

1982 Neurasthenia and Depression: A Study of Somatization and Culture in China. Culture, Medicine and Psychiatry 6: 117-190.

1986 Social Origins of Distress and Disease: Neurasthenia, Depression, and Pain in Modern China. New Haven, CT: Yale University Press.

1988 Rethinking Psychiatry: From Cultural Category to Personal Experience. New York: Free Press. Kleinman, Arthur, and Joan Kleinman

1991 Suffering and Its Professional Transformation: Toward an Ethnography of Interpersonal Experience. Culture, Medicine and Psychiatry 15(3): 275-301.

1999 The Transformation of Everyday Social Experience: What a Mental and Social Health Perspective Reveals about Chinese Communities under Global and Local Change. Culture, Medicine and Psychiatry 23: 7-24. 
Kuo, Wen H., Robert Gray, and Nan Lin

1979 Locus of Control and Symptoms of Psychological Distress among Chinese-Americans. International Journal of Social Psychiatry 25(3): 176-187.

Lakoff, Andrew

2005 Pharmaceutical Reason: Knowledge and Value in Global Psychiatry. New York: Cambridge University Press.

Lau, Joseph Tak Fai, Hi Yi Tsui, P.C. Siah, and K.L. Zhang

2002 A Study on Female Sex Workers in Southern China (Shenzhen): HIV-Related Knowledge, Condom Use and STD History. AIDS Care 14(2): 219-233.

Lee, Ching Kwan

1998 The Labor Politics of Market Socialism-Collective Inaction and Class Experience among State Workers in Guangzhou. Modern China 24(1): 3-33.

Lee, Sing

1999 Diagnosis Postponed: Shenjing Shuairuo and the Transformation of Psychiatry in Post-Mao China. Culture, Medicine and Psychiatry 23: 349-380.

2001 From Diversity to Unity: The Classification of Mental Disorders in 21st-Century China. Psychiatric Clinics of North America 24(3): 421-431.

Lee, Sing, and Hong Yu

1994 Unipolar Mania in Non-Western Cultures. British Journal of Psychiatry 165(3): 413.

Leung, Kwok

1996 The Role of Beliefs in Chinese Culture. In The Handbook of Chinese Psychology. Michael Harris Bond, ed., pp. 247-262. New York: Oxford University Press.

Levy, Robert, and Douglas Hollan

1998 Person-Centered Interviewing and Observation in Anthropology. In Handbook of Methods in Anthropology. H. Russell Bernard, ed., pp. 233-265. Walnut Creek, CA: Altamira Press.

Lin, George C.S.

1997 Red Capitalism in South China: Growth and Development of the Pearl River Delta. Vancouver, Canada: UBC Press.

Lin, Keh-Ming

1981 Traditional Chinese Medical Beliefs and Their Relevance for Mental Illness and Psychiatry. In Normal and Abnormal Behavior in Chinese Culture. Arthur Kleinman and Tsung-Yi Lin, eds., pp. 95-111. Dordrecht, Netherlands: D. Reidel.

Lin, Keh-Ming, and Arthur Kleinman

1981 Recent Developments of Psychiatric Epidemiology in China. Culture, Medicine and Psychiatry 5: 135-143.

Link, Perry, Richard P. Madsen, and Paul G. Pickowicz

2002 Popular China: Unofficial Culture in a Globalizing Society. Landham, MD: Rowman \& Littlefield.

Lu, Henry, trans.

1978 A Complete Translation of The Yellow Emperor's Classic of Internal Medicine and The Difficult Classic. Vancouver, Canada: Academy of Oriental Heritage.

Lu, Yawen, Sing Lee, M.L. Liu, Y.K. Wing, and T.S. Lee

1999 Too Costly to Be Ill: Psychiatric Disorders among Hospitalized Migrant Workers in Shenzhen. Transcultural Psychiatry 36(1): 95-109.

Markus, Hazel Rose, and Shinobu Kitayama

1991 Culture and Self: Implications for Cognition, Emotion, and Motivation. Psychological Review 98(2): 224-253.

Martin, Emily

2007 Bipolar Expeditions: Mania and Depression in American Culture. Princeton, NJ: Princeton University Press.

Murray, Christopher J.L., and Alan D. Lopez, eds.

1996 The Global Burden of Disease: A Comprehensive Assessment of Mortality and Disability from Diseases, Injuries, and Risk Factors in 1990 and Projected to 2020. Cambridge, MA: Harvard University Press.

Ng, Roger M.K., Veronica Pearson, May Lam, C.W. Law, Cindy P.Y. Chiu, and Eric Y.H. Chen

2008 What Does Recovery from Schizophrenia Mean? Perceptions of Long-Term Patients. International Journal of Social Psychiatry 54(2): 118-130. 
Ong, Aihwa

2006 Neoliberalism as Exception: Mutations in Citizenship and Sovereignty. Durham, NC: Duke University Press.

Ong, Aihwa, and Stephen J. Collier, eds.

2005 Global Assemblages: Technology, Politics, and Ethics as Anthropological Problems. Oxford: Blackwell.

Pearson, Veronica

1995 Mental Health Care in China. London: Royal College of Psychiatrists.

Peterson, Christopher, Stanley M. Schwartz, and Martin E. Seligman

1981 Self-blame and Depressive Symptoms. Journal of Personality and Social Psychology 41(2): 253259.

Peterson, Christopher, Steven F. Maier, and Martin E.P. Seligman

1993 Learned Helplessness: A Theory for the Age of Personal Control. New York: Oxford University Press.

Ralston, David A., Carolyn P. Egri, Sally Stewart, Robert H. Terpstra, and Kaicheng Yu

1999 Doing Business in the 21st Century with the New Generation of Chinese Managers: A Study of Generational Shifts in Work Values in China. Journal of International Business Studies 30(2): $415-428$.

Rose, Nikolas

1996 Inventing Ourselves: Psychology, Power and Personhood. p. 33. Cambridge: Cambridge University Press.

1999 Powers of Freedom: Reframing Political Thought. New York: Cambridge University Press.

2003 The Neurochemical Self and Its Anomalies. In Risk and Morality. Richard V. Ericson and Aaron Doyle, eds. Toronto, Canada: University of Toronto Press.

Rotter, Julian B.

1975 Some Problems and Misconceptions Related to the Construct of Internal Versus External Control of Reinforcement. Journal of Consulting and Clinical Psychology 43(1): 55-66.

Sajatovic, Martha, Marilyn Davies, and Debra R. Hrouda

2004 Enhancement of Treatment Adherence among Patients with Bipolar Disorder. Psychiatric Services 55(3): 264-269.

Scheper-Hughes, Nancy

1979 Saints, Scholars, and Schizophrenics: Mental Illness in Rural Ireland. Berkeley: University of California Press.

Shen, Yu-Cun, Ming-Yuan Zhang, Yue-Qin Huang, Yan-Ling He, Zhao-Rui Liu, Hui Cheng, Adley

Tsang, Sing Lee, and Ronald C. Kessler

2006 Twelve-Month Prevalence, Severity, and Unmet Need for Treatment of Mental Disorders in Metropolitan China. Psychological Medicine 36: 257-267.

Shenzhen Government

2006 20\% Locals Suffer Mental Disorder. Shenzhen Government online. Available at: http://english. sz.gov.cn/ln/200610/t20061020_147361.htm. Accessed March 22, 2008.

Sivin, Nathan

1988 Science and Medicine in Imperial China-The State of the Field. Journal of Asian Studies 47(1): 41-90.

1993 Huang Ti Nei Ching. In Early Chinese Texts: A Bibliographical Guide. Michael Loewe, ed., pp. 196-215. Berkeley and Los Angeles: University of California Press.

Thireau, Isabelle, and Linshan Hua

2003 The Moral Universe of Aggrieved Chinese Workers: Workers' Appeals to Arbitration Committees and Letters and Visits Offices. China Journal 50: 83-103.

Unschuld, Paul U.

2003 Huang Di Nei Jing Su Wen: Nature, Knowledge, Imagery in an Ancient Chinese Medical Text. Berkeley and Los Angeles: University of California Press.

Wallston Strudler, Barbara, and Kenneth A. Wallston

1978 Locus of Control and Health: A Review of the Literature. Health Education Behavior 6: 107-117.

Wang, Shaoguang

1995 The Politics of Private Time: Changing Leisure Patterns in Urban China. In Urban Spaces in Contemporary China: The Potential for Autonomy and Community in Post-Mao China. Deborah S. Davis, Richard Kraus, Barry Naughton, and Elizabeth J. Perry, eds., pp. 149-172. New York: Press Syndicate of the University of Cambridge. 
Weems, Carl F., and Wendy K. Silverman

2006 An Integrative Model of Control: Implications for Understanding Emotion Regulation and Dysregulation in Childhood Anxiety. Journal of Affective Disorders 91: 113-124.

Weiss, Mitchell

1997 Explanatory Model Interview Catalogue (EMIC): Framework for Comparative Study of Illness. Transcultural Psychiatry 34(2): 235-263.

Weissman, Myrna M., Roger C. Bland, and Glorisa J. Canino

1996 Cross-National Epidemiology of Major Depression and Bipolar Disorder. Journal of the American Medical Association 276: 293-299.

Weissman, Myrna M., Philip J. Leaf, Gary L. Tischler, D.G. Blazer, Marvin Karno, M.L. Bruce, and L.P. Florio

1988 Affective Disorders in Five United States Communities. Psychological Medicine 18: 141-153.

Wong, Daniel Fu Keung, Chang Ying Li, and He Xue Song

2006 Rural Migrant Workers in Urban China: Living a Marginalised Life. International Journal of Social Welfare 16(1): 32-40.

Wu, Chen-I

1959 New China's Achievements in Psychiatry, Collection of Theses on Achievements in the Medical Sciences in Commemoration of the 10th National Foundation Day of China (Vol. II). Beijing. Translated by U.S. Joint Publications Research Service No. 14,829. (Reprinted In The Minds of the Chinese People. Martha Livingston and Paul Lowinger, eds. Englewood Cliffs, NJ: PrenticeHall, 1983).

Wu, David Y.H.

1982 Psychotherapy and Emotion in Traditional Chinese Medicine. In Cultural Conceptions of Mental Health and Therapy. Anthony J. Marsella and Geoffrey M. White, eds., pp. 285-301. New York: Springer.

Yan, Yunxiang

2003 Private Life under Socialism: Love, Intimacy, and Family Change in a Chinese Village 19491999. Stanford, CA: Stanford University Press.

Yang, Kuo-Shu

1996 The Psychological Transformation of the Chinese People as a Result of Societal Modernization. In The Handbook of Chinese Psychology. Michael Harris Bond, ed., pp. 479-498. New York: Oxford University Press.

Young, Allan, and Laurence J. Kirmayer

1996 Illness Narrative Interview Protocols. Unpublished manuscript. Culture and Mental Health Research Unit, Department of Psychiatry, Sir Mortimer B. Davis-Jewish General Hospital, Montréal.

Zhao, Shukai

2000 Criminality and Policing of Migrant Workers. China Journal 43: 101-110.

Zola, Irving Kenneth

1972 Medicine as an Institution of Social Control. Sociological Review 20(4): 487-504. 